\title{
Communication and Innovation in Cooperatives
}

\author{
Xiao Peng $^{1,2}$ • George Hendrikse ${ }^{1}$ • Wendong Deng ${ }^{1}$
}

Received: 27 November 2015 /Accepted: 1 August 2016 /

Published online: 20 September 2016

(C) The Author(s) 2016. This article is published with open access at Springerlink.com

\begin{abstract}
Cooperatives differ in their intensity of horizontal and vertical communications, their innovation policies, and their centralization of decision-making power. We aim to establish relationships between these communication, innovation, and decision-making aspects of cooperatives, and to identify the circumstances when a particular configuration adds most value. Horizontal and vertical communications are analyzed in a decentralized and centralized cooperative. Horizontal communication (HC) is characterized as the exchange of information between farmers in the society of members. It is associated with process innovation. Vertical communication (VC) is the exchange of information between a member and the CEO of the cooperative enterprise. It is associated with product innovation. The CEO decides regarding the deliveries of the member and the level of vertical communication in the centralized cooperative, while these decisions are taken by the members in the decentralized cooperative. We establish that the decentralized cooperative is efficient at an intermediate level of the $\mathrm{VC}$ cost coefficient and when the HC cost coefficient is above a certain level, while the centralized cooperative is efficient in the other cases.
\end{abstract}

Keywords Agricultural cooperatives · Communication · Innovation · Decentralization

\footnotetext{
Xiao Peng

xpeng@rsm.nl

George Hendrikse

ghendrikse@rsm.nl

Wendong Deng

wdeng@rsm.nl
}

1 Rotterdam School of Management, Erasmus University, Rotterdam, Netherlands

2 Department of Organization and Personnel Management, Burgemeester Oudlaan 50, 3062PA Rotterdam, Netherlands 


\section{Introduction}

The organizational communication literature establishes that communication is one crucial element of organizational governance (Christensen and Cornelissen 2011; Jablin and Putnam 2001). White (1997) states that organizations can themselves be regarded as communication structures. Organizations cannot exist without communication, i.e., they come into existence in the interaction that takes place between organizational members and as a result of the communication between them. The wholeness of an organization shows a consistent and coherent image of what the organization is. Communication brings every part of the organization to the same level of understanding and therefore allows the organization to achieve consistency and coherence (Schultz et al. 1994).

This paper analyses communication in cooperatives. A cooperative is an enterprise collectively owned by a society of members having a transaction relationship with it (Helmberger and Hoos 1962; Hendrikse and Feng 2013; Robotka, 1947). The cooperative's main function is to process the products from its members and then sell them to the customers. However, members are themselves business enterprises and economic units. An agricultural cooperative is therefore an enterprise collectively owned (vertical relationship) by an association of many independent upstream agricultural producer enterprises (horizontal relationship). Communication is essential to keep the cooperative working in the members' interests. Members who lack understanding of its practices are likely to have a negative attitude towards their cooperative, and this may cause poor performance (Goodman 1994). Not only the communication among the members themselves but also the communication between the members and the cooperative management is important (Cechin, Bijman, Pascucci, and Omta 2013).

Cremer, Garicano, and Prat (2007) and Garicano and Wu (2012) provide an organizational economics explanation of communication within an organization. They distinguish HC and VC. HC is defined as peer-to-peer communication among specialists with common codes, or overlapping knowledge, to share information in order to solve problems efficiently which cannot be done by a single specialist with limited knowledge. VC is defined as communication between the peers and an external higher up "translators." Only when the knowledge is beyond the field of the specialists and costly to codify, does VC become necessary to facilitate the matching between problems and solutions. Patrucco (2008) also mentioned that the technical communication between the internal investments in $R \& D$ and the technologies provided by an external party is a crucial strategy for increasing returns in the production of knowledge.

These two types of communication have an impact on different parts of the supply chain. HC is defined as the information exchange between farmers about their production methods. Farmers communicate with each other to share their production knowledge. This may decrease their own (marginal) production costs at the upstream stage of production. From the innovation perspective, this belongs to individual (small scale) innovation (Pelz et al. 1978). We associate, therefore, HC with process innovation. VC is the communication between the members (the farmers with superior production knowledge) and the CEO (with superior marketing experience). When the cooperative takes more responsibilities for the product than simply product sale, product innovation is gradually taken over by the CEO. Production innovation activities include quality control and development of new varieties in order to increase the price and demand in 
the market at the final stage of production. From the innovation perspective, this belongs to group (big scale) innovation (Pelz et al., 1978). We associate, therefore, VC with product innovation. Specifically, the farmers and the CEO exchange information about the development of the product. On the one hand, the CEO organizes the research regarding the product from the customer perspective and sets up a research unit to develop the new production method. He is important in deciding what the farmers produce and then shares the technological knowledge with the farmers. On the other hand, the farmers provide feedback from the field, and collaborate with the CEO regarding product development. To summarize, the concept of $\mathrm{HC}$ and $\mathrm{VC}$ in this paper relates to two perspectives: (1) $\mathrm{HC}$ and $\mathrm{VC}$ reflect the horizontal relationship and vertical relationship in a cooperative organization and (2) $\mathrm{HC}$ and $\mathrm{VC}$ contribute to different types of innovation.

Observing the history of agricultural cooperatives, many governance structures have been adopted in this organization. Bijman et al. (2013) discuss the governance structure in cooperatives regarding the allocation of decision right between the board of directors (representing the members) and the professional management. Chaddad and Iliopoulos (2013) also address the delegation of formal and real authority to non-patron, professional managers as a key to improving the efficiency of collective decision-making in cooperatives. In this paper, we study communication in two structures: decentralized and centralized cooperatives. We define (de)centralization in terms of the allocation of decision rights regarding innovation and production. Farmers decide regarding their own product innovation and production in a decentralized structure, while the farmers authorize the CEO to make product innovation and production decisions for the cooperative in a centralized structure.

Alonso et al. (2008) compare centralized and decentralized coordination when managers communicate strategically. They distinguish HC as communication between the division managers and $\mathrm{VC}$ as communication between the division managers and the headquarter. Moreover, $\mathrm{HC}$ emerges when coordination is decentralized, while VC emerges when coordination is centralized. The result shows that a higher need for coordination can improve $\mathrm{HC}$ in a decentralized structure but goes at the expense of centralization benefits. Specifically, under decentralization an increase in the need for coordination makes the managers more willing to listen to each other to avoid costly coordination failures. In contrast, under centralization, when coordination becomes more important, the headquarter increasingly ignores the division managers' information about their own divisions. This induces each manager to exaggerate his case more, which, in turn, leads to less information being exchanged. Unlike Alonso et al. (2008), we propose HC and VC exist in both structures, and we compared the level of $\mathrm{HC}$ and $\mathrm{VC}$ in the two structures. Moreover, we relate $\mathrm{HC}$ and $\mathrm{VC}$ to process and product innovation.

We examine how $\mathrm{HC}$ and $\mathrm{VC}$ contribute to process and product innovation and how it differs between decentralized and centralized cooperatives. The role of $\mathrm{VC}$ is to increase final product demand by product innovation, while HC leads to upstream process innovation by decreasing production cost. The conceptual model linking the variables is presented in Fig. 1. It is in line with the framework presented by (Williamson 2000) in the sense that short run decisions are embedded in long run decisions. However, we provide more details by highlighting and positioning the role of communication. Two questions are addressed. First, how do the communication and 


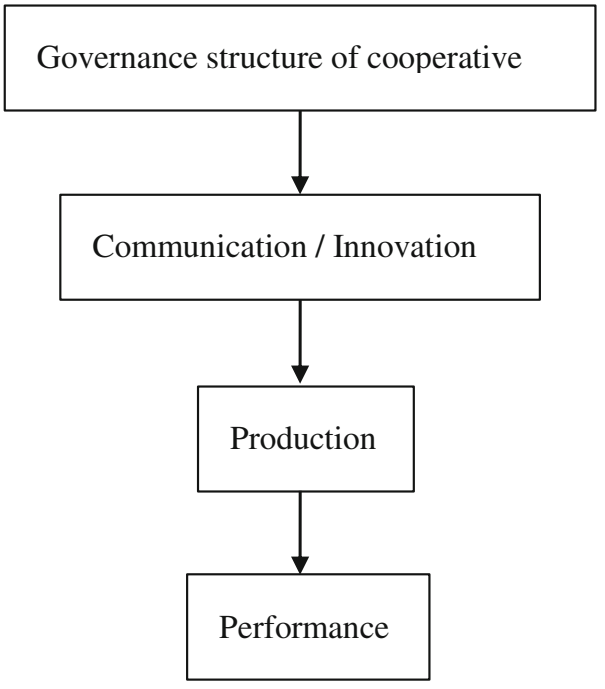

Fig. 1 Conceptual model

production decisions differ between the two governance structures? Second, what determines the efficient governance structure? In order to answer these questions, we develop a three-stage non-cooperative model with two farmers and a CEO. In the first stage, the efficient governance structure is determined; in the second stage, the $\mathrm{HC}$ and VC levels are decided; in the last stage, the production level is determined.

The paper is organized as follows. The "De Producent and Harvest House" section presents two cases of cooperatives to illustrate the relevance of different communication structures. The "Model" section presents the model regarding HC and VC. The "Equilibrium" section derives the equilibrium production and communication levels, and determines the efficient governance structure. The "De Producent Versus Harvest House" section relates the two cases to the model. Finally, conclusions are formulated in "Conclusion and Future Research."

\section{De Producent and Harvest House}

We present a description of two cooperatives to illustrate the relevance of different types of innovation, communication, and the relationship with decision-making. ${ }^{1}$

\section{De Producent}

De Producent is a cheese cooperative. The turnover of De Producent was around 11 million euros in 2013. De Producent consists of 40 large members and 10 small, not active members. The membership is therefore homogeneous. They are individual farmers located in a radius of $100 \mathrm{~km}$ around Gouda. The dairy farmers produce their

\footnotetext{
${ }^{1}$ We visited cooperative De Producent on April, 28, 2014 and talked with the director Jacco Bot. We visited cooperative Harvest House on January 23, 2015 and talked with general director Jelte van Kammen and financial director Fons van der Vleuten.
} 
own cheese, while the storage/processing of the cheese and the transportation of the cheeses to wholesalers and retailers are done by the cooperative.

The decision structure of this cooperative can be characterized as centralized. The current general manager is not a farmer member. Instead, he is a professional manager with years of experience in the agricultural industry. Substantial decision power is delegated to the general manager, including the day-to-day operational decisions and the decision of whether to increase the cheese delivery of a member in the next year. He formulates a proposal regarding the retained earnings percentage, which is to be approved in the General Assembly meeting. The members are obligated to deliver $100 \%$ of their cheese to the cooperative. This bylaw has been in place since the birth of the cooperative. However, the general manager mentioned that "I am not a policeman." If outside delivery is detected, the management will just talk to the member and no financial punishment is imposed.

The cooperative pays substantial attention to product innovation. The cheese quality is independently checked by two full-time employees based on three criteria: shape, taste, and consistency. The quality is also monitored. Each farm is checked approximately 2 full days a year by the two employees, and quality improvement advice is provided by a quality enhancement program. Via these measures, the cooperative helps members to improve the production process at the farm. Next to the quality innovation, a research team is organized for developing new products with new flavors. Usually, the cooperative will select two members to trial the production of a new product. After that, it spreads the production technology to all members.

There is a lot of communication between the general manager and the members, i.e., $\mathrm{VC}$ is intense. The cooperative sends a "weekly quality form" to every farmer. According to the general manager, "the cooperative is transparent about everything and farmers can check everything." The general manager spends $50 \%$ of his time in communicating with the members, largely via phone calls and farm visits. The members do not like to use the Internet. The members trust the general manager/cooperative and share information with the cooperative. An important reason is that developing specialty cheeses has become financially very attractive, and therefore, product innovation has gained in importance. The 40 active members know each other, but there is not much communication and information exchange between them. In fact, most of the farms grew to big enterprises in the past 10 15 years. Some of them have annual revenue of more than 1 million Euros. The growing size has limited communication between the farmers. Moreover, the CEO observes competition between members because everyone wants to deliver more cheese to the cooperative. It is known from the literature that the larger number of the participants in one project, the more direct competition among them, and it leads to less information exchange regarding "precompetitive" data (Prosser, 1995).

\section{Harvest House}

Harvest House specializes in vegetables. It has 826 ha under cultivation, and a turnover of 530 million euros in 2013. The membership consists of four product groups and, in total, 67 growers. First, there are 52 paprika growers, including 5 large growers. Second, there are 11 tomato growers, including 5 large growers. Finally, there are 2 cucumber growers and 2 eggplant growers. The membership is therefore heterogeneous, within and between product groups. 
The decision structure of this cooperative can be characterized as decentralized. A lot of decision power is not granted to the CEO by the farmers. The different product groups organize their own logistics and packaging centers. There is competition between these centers because they are allowed to choose between these centers. For instance, if one of the packaging companies within the cooperative is able to offer a lower price, other growers are free to choose its services. In this way, the packaging seems to be efficient (Bulow and Klemperer 1996). Growers decide the quantity to be delivered, and the cooperative is obliged to sell them. The management is responsible for the quality control in the cooperative, but it does not command farmers about how to resolve a given quality problem. For example, the management may communicate to the grower that his product lacks certain taste characteristics, or may suffer from early perishability, but will leave it up to the grower to find a solution. The growers may of course consult with each other regarding such problems or raise an issue in the product committee. The reason for such allocation of control is the growers' better knowledge about the growing process and technology. Additionally, members are open to other growers' advice and continuously learn from each other.

Two product groups are set up for product-related matters. When there is a problem regarding a product, the cooperative does not take the responsibility to resolve it. The members discuss with each other in order to find a solution themselves. It generates high commitment and trust in the coop community. It contributes to improving the products. Therefore, members take the innovation decisions regarding production processes and product development. For example, some growers are involved in the product project Agriport A7. Agriport A7 is the site of a development project for large-scale greenhouse and open-field crop cultivation. The large-scale production of fresh vegetables, processing, and logistics have been clustered at Agriport A7, and it is considered the most modern agro-park in the world. Additionally, Harvest House focuses largely on sustainability, which is market-driven.

The coop provides many communication channels. Formally, the General Assembly meeting is organized two times a year. Once a month, there is a product meeting, product groups attend the meeting and discuss price and quality and product competition issues. A newsletter is delivered to every member once a week, to report the weekly activities. Informally, the CEO visits every member once in a while. Besides, a digital platform is being built for better interaction within the coop. From the CEO's observation, $\mathrm{HC}$ is intensive and very much valued. Members themselves communicate a lot due to that they actively join the organizational activities and make most of the decisions. VC is relatively low because less information exchange is needed between the cooperative and the members.

Table 1 summarizes the differences between the two cooperatives.

\section{Model}

Consider a cooperative in a monopolistic market. The cooperative consists of a CEO and two farmer members. There are two types of communication in a cooperative. 
Table 1 De Producent versus Harvest House

\begin{tabular}{llll}
\hline & Attributeslcase & De Producent & Harvest House \\
\hline \multirow{2}{*}{ Facts } & Product & Cheese & Vegetables \\
& Turnover 2013 & $€ 11$ million & $€ 530$ million \\
& \#Members & 50 & 67 \\
Assessment & Member heterogeneity & Low & High \\
& Governance structure & Centralized & Decentralized \\
& Innovation support & High & Low \\
& HC level & Low & High \\
& VC level & High & Low \\
\hline
\end{tabular}

Horizontal communication between farmers is geared towards improving knowledge regarding the production process, i.e. process innovation. It results in reducing his production cost. Vertical communication between a farmer and the CEO generates knowledge regarding product innovation. Product innovation will increase the price of the products in the market. Figure 2 shows the channels of communication in a cooperative. There are two types of cooperatives. In the decentralized cooperative, farmer 1 chooses to communicate $\left(h_{1}\right)$ with farmer 2 to improve his knowledge regarding his production process, i.e., process innovation. It results in reducing his production cost. The same decision has to be made by farmer $2\left(h_{2}\right)$. The HC decisions $h_{1}$ and $h_{2}$ are made simultaneously. Meanwhile, farmers 1 and 2 have to choose the intensity of communication with the CEO $\left(v_{1}\right.$ and $\left.v_{2}\right)$ to obtain knowledge regarding product innovation. Product innovation will increase the price of the products in the market. In the centralized cooperative, farmers 1 and 2 choose the intensity of the communication between each other to enable process innovation, while the CEO determines the product development by deciding the $\mathrm{VC}$ levels $\left(v_{1}, v_{2}\right)$ for the cooperative.

A three-stage game is developed to study $\mathrm{HC}$ and $\mathrm{VC}$, innovation, and decisionmaking in a centralized and a decentralized cooperative. In the first stage, the governance structure decentralized (D) or centralized (C) cooperative is determined. In the second stage, the $\mathrm{HC}$ and $\mathrm{VC}$ decisions are determined simultaneously. Define $h_{i}\left(v_{i}\right)$ as the level of HC (VC) regarding farmer $i$, where $i=1,2$. Define $\bar{h}(\bar{v})$ as the average level of horizontal (vertical) communication. The HC decisions are taken by the farmers in

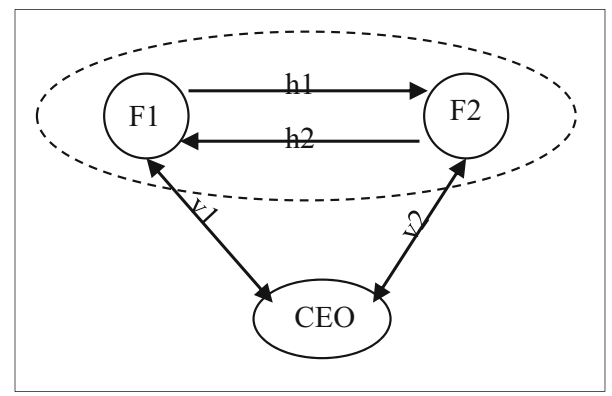

Fig. 2 Communication in the cooperative 
both cooperatives, while farmers decide $\mathrm{VC}$ in the decentralized cooperative and the $\mathrm{CEO}$ is determining $\mathrm{VC}$ in the centralized cooperative. In the third stage, the farmers choose their own level of production independently and simultaneously in the decentralized structure $\left(q_{1}, q_{2}\right)$, while the CEO decides the production level $q_{1}$ and $q_{2}$ in the centralized structure. Figure 3 depicts the sequence of decisions.

The market demand function is inspired by the seminal product differentiation model of Mussa and Rosen (1978), which is summarized by Mérel, Saitone, and Sexton (2009). It is defined as $p=(\bar{v}+d)-Q$, where $d(>0)$ is the basic demand parameter and $Q(>0)$ is the quantity demanded. When $v_{1}\left(v_{2}\right)$ increases, more product innovation is created, and the consumers are willing to pay more for the new product.

Define the cost of $\mathrm{VC}$ as $V_{i}=\frac{1}{2} k v_{i}^{2}$, where $i=1,2$ and $k$ is the $\mathrm{VC}$ cost coefficient $(k>0)$. The second derivative of the cost of $\mathrm{VC}$ is $V_{i}^{\prime \prime}=k$, i.e., the marginal cost of $\mathrm{VC}$ is increasing. $V_{i}^{\prime \prime}$ can be interpreted as the discretion of the farmer regarding the choice and execution of activities between the farm and the cooperative enterprise, like upgrading deliveries, facilitating transportation, and dealing with intermediate product peculiarities. A high value of $k$ shows that additional VC is accompanied by a large increase in costs. An example is a bureaucratic organization (Milgrom \& Roberts, 1992, p122). In general, $k$ will be smaller as the size of the membership is smaller, or when member homogeneity is higher.

The production cost of farmer $i$ is $C_{i}=c_{i} q_{i}$. The farmers talk to each other in order to improve their production process. It decreases their (marginal) production cost. $\mathrm{HC}$ is therefore to be interpreted as process innovation by decreasing the members' marginal production cost to $c_{i}=A-h_{i}$ (Falvey, Poyago-Theotoky, and Teerasuwannajak 2013), where A is a base cost (i.e., the production cost when there is no process innovation). It is assumed that process innovation cannot decrease the marginal production cost to zero, i.e., $0<h_{i}<A$. Define the $\mathrm{HC}$ cost

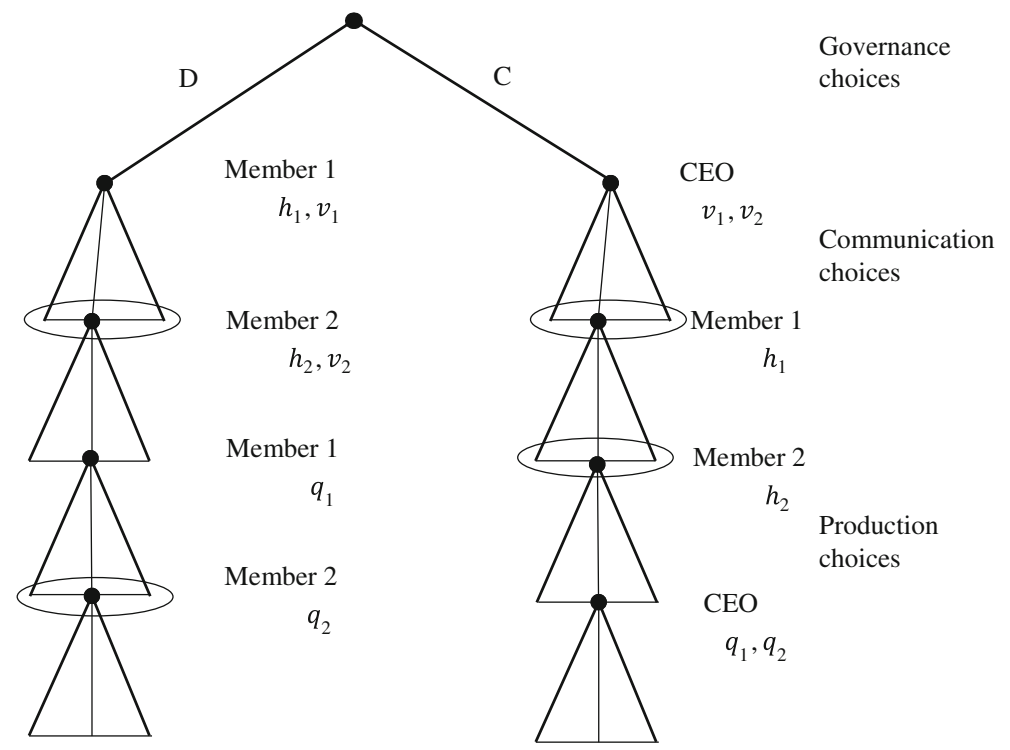

Fig. 3 The three-stage game 
function for the farmer $i$ as $H_{i}=\frac{1}{2} r h_{i}^{2}$, where $r$ is the HC cost coefficient $(r>0)$. The payoff of farmer $i$ is therefore $\pi_{i}=(\bar{v}+d-Q) q_{i}-c_{i} q_{i}-\frac{1}{2} r h_{i}^{2}-\frac{1}{2} k v_{i}^{2}$.

\section{Equilibrium}

The concept of subgame perfect equilibrium is used to solve the game. We start therefore with determining the equilibrium production levels and communication levels in the "Decentralized cooperative" and the "Centralized Cooperative." The mathematical details are presented in the appendix. Comparative statics results are formulated in "Communication levels."

\section{Decentralized Cooperative}

\section{Production Levels}

In the final stage, each farmer determines his optimal production level by maximizing his own payoff. The first-order condition results in the best-response functions

$q_{1}^{*}\left(q_{2}\right)=\frac{1}{2}\left(d-A+\bar{v}+h_{1}\right)-\frac{1}{2} q_{2}$

and

$q_{2}^{*}\left(q_{1}\right)=\frac{1}{2}\left(d-A+\bar{v}+h_{2}\right)-\frac{1}{2} q_{1}$

The quantity competition between the enterprises is reflected in the negative slope of the reaction functions. Notice that the reaction function of farmer 1 (2) shifts outward as a function of $v_{1}, v_{2}, h_{1}\left(h_{2}\right)$.

The intersection of the reaction functions determines the Nash equilibrium production levels:

$q_{1}^{*}=\frac{1}{3}\left(d-A+\bar{v}+2 h_{1}-h_{2}\right)$

and

$q_{2}^{*}=\frac{1}{3}\left(d-A+\bar{v}+2 h_{2}-h_{1}\right)$.

The best-response functions of farmer 1 and farmer 2 and the equilibrium production levels are presented in Fig. 4. Notice that $q_{1}^{*}\left(q_{2}^{*}\right)$ is positively related to $v_{1}, v_{2}, h_{1}\left(h_{2}\right)$, and negatively related to $h_{2}\left(h_{1}\right)$.

\section{Communication Levels}

The communication levels are determined in the second stage of the game. Substituting $q_{1}^{*}, q_{2}^{*}$ into $\pi_{1}^{*}$ and $\pi_{2}^{*}$, and maximizing $\pi_{1}^{*}$ and $\pi_{2}^{*}$ with respect to the communication 


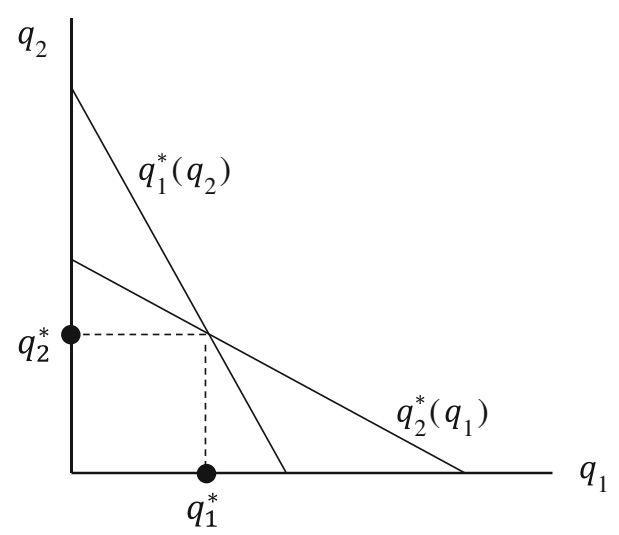

Fig. 4 Best-response functions

variables $h_{1}, h_{2}, v_{1}$ and $v_{2}$ results in four first-order conditions. The equilibrium levels of communication are

$$
h_{1}^{*}(k, r \mid D)=h_{2}^{*}(k, r \mid D)=\frac{4(d-A)}{r(9-1 / k)-4}
$$

and

$v_{1}^{*}(k, r \mid D)=v_{2}^{*}(k, r \mid D)=\frac{(d-A)}{k(9-4 / r)-1}$.

Substituting $h_{1}^{*}, h_{2}^{*}, v_{1}^{*}, v_{2}^{*}$ into $q_{1}^{*}$ and $q_{2}^{*}$, we obtain the Nash equilibrium production levels $q_{1}^{*}(k, r \mid D)=q_{2}^{*}(k, r \mid D)=\frac{3(d-A)}{9-4 / r-1 / k}$

Substituting the above results into the payoffs, we obtain the total payoff of the decentralized cooperative

$\pi^{*}(k, r \mid D)=\pi_{1}^{*}+\pi_{2}^{*}=\frac{(d-A)^{2}(18-16 / r-1 / k)}{(9-4 / r-1 / k)^{2}}$

\section{Centralized Cooperative}

The VC level is determined by the CEO and the cost is shared equally by the farmers, while the HC level is determined by each farmer and the cost is paid by each farmer. The CEO chooses the production levels $q_{1}$ and $q_{2}$ in order to maximize the payoff of the cooperative. 


\section{Production Levels}

The payoff of the cooperative can be written as $\pi=\pi_{1}+\pi_{2}=(\bar{v}+d-Q)\left(q_{1}+q_{2}\right)-c_{1} q_{1}-c_{2} q_{2}-\frac{1}{2} r h_{1}^{2}-\frac{1}{2} r h_{2}^{2}-\frac{1}{2} k\left(v_{1}+v_{2}\right)^{2}$.

The payoffs of the farmers are

$$
\begin{aligned}
& \pi_{1}=(\bar{v}+d-Q) q_{1}-c_{1} q_{1}-\frac{1}{2} r h_{1}^{2}-\frac{1}{4} k\left(v_{1}+v_{2}\right)^{2}, \\
& \pi_{2}=(\bar{v}+d-Q) q_{2}-c_{2} q_{2}-\frac{1}{2} r h_{2}^{2}-\frac{1}{4} k\left(v_{1}+v_{2}\right)^{2} .
\end{aligned}
$$

The first-order condition results in the best-response functions

$q_{1}^{*}\left(q_{2}\right)=\frac{1}{2}\left(d-A+\bar{v}+h_{1}\right)-q_{2}$

and

$q_{2}^{*}\left(q_{1}\right)=\frac{1}{2}\left(d-A+\bar{v}+h_{2}\right)-q_{1}$.

Focusing on the symmetric equilibrium outcomes results in $q_{1}^{*}=q_{2}^{*}=\frac{1}{4}(d-A+\bar{v}+\bar{h})$.

\section{Communication Levels}

Substituting $q_{1}^{*}$ and $q_{2} *$ into $\pi, \pi_{1}, \pi_{2}$, farmers maximize their own payoffs with respect to $h_{1}, h_{2}$, while the CEO maximizes the total payoff with respect to $v\left(v=v_{1}+v_{2}\right)$. We get from the three first order conditions the equilibrium

$h_{1}^{*}(k, r \mid C)=h_{2}^{*}(k, r \mid C)=\frac{2(d-A)}{r(8-1 / k)-2}$

and

$v^{*}(k, r \mid C)=\frac{2(d-A)}{k(8-2 / r)-1}$.

Substituting the results back into $q_{1}^{*}$ and $q_{2}^{*}$, we obtain the equilibrium centralized production level $q_{1}{ }^{*}(k, r \mid C)=q_{2}{ }^{*}(k, r \mid C)=\frac{2(d-A)}{8-2 / r-1 / k}$. Lastly, substitution of the above results in the total payoff of the centralized cooperative results in $\pi^{*}(k, r \mid C)=\frac{2(d-A)^{2}}{8-2 / r-1 / k}$.

To summarize the equilibrium choices and payoffs, we list $\mathrm{HC}, \mathrm{VC}$, production and profit as functions of $r$ and $k$ in the (de)centralized structure in Table 2. 
Table 2 Equilibrium choices and payoffs in the decentralized/centralized cooperative

\begin{tabular}{lcc}
\hline Cooperative & Decentralized structure & Centralized structure \\
\hline Production & $\frac{6(d-A)}{9-4 / r-1 / k}$ & $\frac{4(d-A)}{8-2 / r-1 / k}$ \\
HC & $\frac{8(d-A)}{r(9-1 / k)-4}$ & $\frac{4(d-A)}{r(8-1 / k)-2}$ \\
VC & $\frac{2(d-A)}{k(9-4 / r)-1}$ & $\frac{2(d-A)}{k(8-2 / r)-1}$ \\
Profit & $\frac{(d-A)^{2}(18-16 / r-1 / k)}{(9-4 / r-1 / k)^{2}}$ & $\frac{2(d-A)^{2}}{8-2 / r-1 / k}$ \\
\hline
\end{tabular}

In order to have meaningful result (by having positive values for all variables), assume that $d>A>0$ and the parameters $k, r$ satisfy $\left\{\begin{array}{c}\frac{1}{8}<k \leq \frac{1}{7}, r>\frac{2 k}{8 k-1} \\ \frac{1}{7}<k \leq \frac{1}{6}, r>\frac{4 k}{9 k-1} \\ k>\frac{1}{6}, r>\frac{16 k}{18 k-1}\end{array}\right.$.

\section{Comparative Statics}

This section formulates results regarding the level of production, $\mathrm{HC}, \mathrm{VC}$, and profit in the decentralized and centralized cooperatives. We start with formulating a result regarding the level of production and profit in the decentralized and centralized cooperative, given the $\mathrm{HC}$ and VC levels. First, the production level in the decentralized cooperative is $\frac{2}{3}(d-A+\bar{v}+\bar{h})$, and it is higher than the production level $\frac{1}{2}(d-A+\bar{v}+\bar{h})$ in the centralized cooperative. ${ }^{3}$ This aligns with the overproduction problem of the decentralized cooperative (Albæk and Schultz 1998). When farmers are making production decisions, they tend to produce more to achieve a higher payoff for themselves, ignoring the negative externalities for the entire membership. Proposition 1 states this result.

Proposition 1 The production level is higher in the decentralized cooperative than in the centralized cooperative, given the levels of communication.

The difference between the joint profit of the centralized cooperative and the decentralized cooperative is $\frac{1}{36}(d-A+\bar{v}+\bar{h})^{2}-k \bar{v}^{2}$, given the HC and VC levels. Therefore, given the communication levels, the centralized cooperative has a higher profit than the decentralized cooperative when $k$ is small. The benefit of the centralized cooperative

\footnotetext{
${ }^{2}$ Given that $d-A>0, r>0, k>0$, let both the denominators and the numerators be positive, we achieve $\left\{\begin{array}{l}\frac{1}{8}<k \leq \frac{1}{7}, r>\frac{2 k}{8 k-1} \\ \frac{1}{7}<k \leq \frac{1}{6}, r>\frac{4 k}{9 k-1} . \\ k>\frac{1}{6}, r>\frac{16 k}{18 k-1}\end{array}\right.$.

${ }^{3}$ The proofs of the propositions are presented in the appendix.
} 
is the internalization of the negative production externalities of individual profit maximization in the decentralized cooperative. However, when $k$ is above a certain level, the centralized cooperative will have a lower profit than the decentralized cooperative due to the increasing marginal cost of $\mathrm{VC}$. The reason is that the CEO is doing all the $\mathrm{VC}$ in the centralized cooperative and carries all the cost, while each farmer carries his own $\mathrm{VC}$ cost in the decentralized cooperative. The result is formulated in proposition 2 .

Proposition 2 The profit level is higher in the centralized cooperative than in the decentralized cooperative when $k$ is small, given the levels of communication.

The understanding of the results is facilitated by first addressing the relationship between $\mathrm{VC}$ and production. This is done by taking the $\mathrm{HC}$ equal to 0 in both cooperatives. We present the equilibrium $\mathrm{VC}$, production, and profit levels in the proposition $3-5$.

The difference between the level of VC in the centralized and decentralized cooperative is determined by the trade-off in the decentralized cooperative between the (unattractive) free riding due to the positive quality enhancement externality of the $\mathrm{VC}$ choices by the members and the (attractive) decentralized payments of the costs of $\mathrm{VC}$ by the members preventing to a certain extent the increasing marginal cost of VC. However, the first order conditions result in $V C_{D}=\frac{2(d-A)}{9 k-1}$ and $V C_{C}=\frac{2(d-A)}{8 k-1}$, i.e. the level of $\mathrm{VC}$ is always higher in the centralized cooperative than in the centralized cooperative for all possible values of the VC cost coefficient $\mathrm{k}$. This result is presented in proposition 3 . The dominance of the free riding effect in determining the level of $\mathrm{VC}$ is due to the specification of the cost function of VC. ${ }^{4}$

Proposition 3 presents the result regarding the level of VC.

Proposition 3 The VC level is higher in the centralized cooperative than in the decentralized cooperative, given the level of $\mathrm{HC}$.

Proposition 1 states that the decentralized cooperative produces more than the centralized cooperative, given the levels of communication. However, this result may be reversed when the choice of $\mathrm{VC}$ is endogenized. We have established that the production level is positively related to the average $\mathrm{VC}$ level $\left(Q_{D}=\frac{2}{3}\left(d-A+\overline{v_{D}}\right), Q_{C}=\frac{1}{2}\left(d-A+\overline{v_{C}}\right)\right)$. An investment in VC creates, therefore, a positive quality enhancement externality. Lower level of $\mathrm{VC}$ due to the free riding in the decentralized cooperative leads to a lower price is paid by consumers for a unit of the product, and this reduces the incentive to overproduce. When the CEO in the centralized cooperative is not overburdened, i.e. $k$

\footnotetext{
${ }^{4}$ A straightforward way to illustrate this is to introduce a capacity constraint for individuals regarding the level of VC. For example, the level of VC in the centralized cooperative is lower than in the decentralized cooperative when the cost function is $V_{i}=\frac{1}{2} k v_{i}^{2}$ when $k<\frac{3(d-A)}{2(9 k-1)}$ and $V_{i}=\infty$ otherwise.
} 
is sufficiently low, then the centralized cooperative produces more than the decentralized cooperative. This is reflected in the equilibrium output levels $Q_{D}$ $=\frac{6(d-A)}{9-1 / k}$ and $Q_{C}=\frac{4(d-A)}{8-1 / k}$. Specifically, the centralized cooperative produces more when $k<\frac{1}{6}$. Proposition 4 summarizes this result.

Proposition 4 The production level is higher (lower) in the decentralized cooperative than in the centralized cooperative when $k>(<) \frac{1}{6}$, given the level of $H C$.

The profit is higher in the decentralized cooperative than in the centralized cooperative, i.e., $\frac{(d-A)^{2}(18-1 / k)}{(9-1 / k)^{2}}>\frac{2(d-A)^{2}}{8-1 / k}$, when $k \in\left(\frac{5-\sqrt{7}}{18}, \frac{5+\sqrt{7}}{18}\right)$. The level of profit of the two governance structures is determined by a number of factors. The centralized cooperative has two advantages. First, it internalizes the negative production externalities of decentralized production decisions by the members (proposition 1). Second, the higher level of VC in the centralized cooperative than in the decentralized cooperative (proposition 3 ) results in higher price per unit sold. However, a higher level of VC is expensive for the centralized cooperative due to the increasing marginal cost of $\mathrm{VC}$ (proposition 2). The high cost of VC dominates the two advantages when $\frac{5-\sqrt{7}}{18}<k<\frac{5+\sqrt{7}}{18}$, i.e., the decentralized cooperative has higher profits when $k$ is at an intermediate level. Finally, the overproduction and the underinvestment in $\mathrm{VC}$ in the decentralized cooperative dominate the higher cost of $\mathrm{VC}$ in the centralized cooperative when $k>\frac{5+\sqrt{7}}{18}$. The reason is that the equilibrium level of $\mathrm{VC}$ is inversely related to $k$, and therefore, the total costs of $\mathrm{VC}$ are decreasing when $\mathrm{k}$ is increasing. Therefore, the centralized cooperative has the highest profits when $k$ is sufficiently high. The result is formulated in proposition 5 .

Proposition 5 The profit level is higher (lower) in the decentralized cooperative than in the centralized cooperative when $k \in\left(\frac{5-\sqrt{7}}{18}, \frac{5+\sqrt{7}}{18}\right)$ (otherwise), given the level of $H C$.

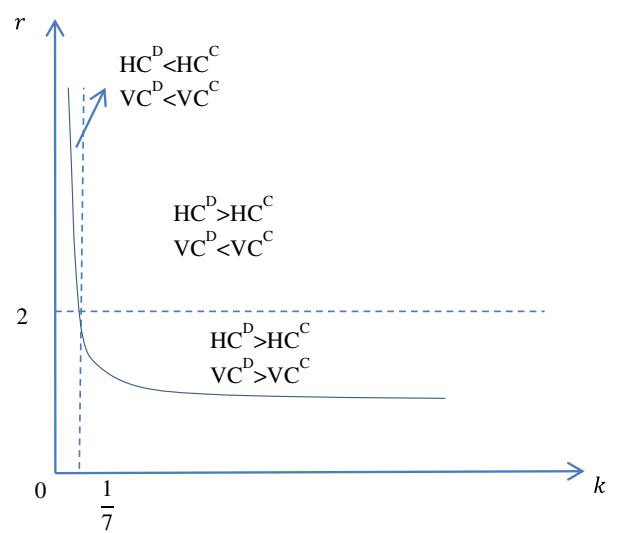

Fig. 5 Comparison of $\mathrm{HC}$ and $\mathrm{VC}$ levels in the two governance structures 
Next, we address both $\mathrm{HC}$ and VC. The next two propositions formulate results regarding the equilibrium communication levels in the second stage of the game, anticipating the production level decisions in the final stage of the game.

The centralized and decentralized cooperative are identical regarding $\mathrm{HC}$ in the sense that each member chooses its level of $\mathrm{HC}$ and pays for the costs. It involves an indirect negative externality because a higher level of $\mathrm{HC}$ reduces the cost of production, and therefore will result in a higher output level, but the costs of the resulting decrease in the price paid by the consumers is carried also by the other member. This results in too much production, and is the (indirect) negative externality in the choice of production due to the choice of horizontal communication. This effect is qualitatively the same for both cooperatives. However, the level of $\mathrm{HC}$ differs between the two cooperatives because the VC and production choices differ between the two cooperatives. Figure 5 presents the comparison between the two cooperatives regarding their equilibrium communication choices (proof see appendix).

Next, we compare the equilibrium production level in the two cooperatives. Similar to proposition 4, both $\mathrm{VC}$ and $\mathrm{HC}$ counter the overproduction effect. We have shown that the production level is positively related to both the $\mathrm{HC}$ and $\mathrm{VC}$ level $\left(Q_{D}=\frac{2}{3}\left(d-A+\overline{v_{D}}+\overline{h_{D}}\right), Q_{C}=\frac{1}{2}\left(d-A+\overline{v_{C}}+\overline{h_{C}}\right)\right)$. When $k$ increases, more VC free-riding problems occur in the decentralized cooperative, and it reduces the production. Moreover, when $r$ increases, the indirect negative HC externality is weakened, less process innovation occurs in both cooperatives, and it reduces the overproduction. Therefore, the production level decreases in both cooperatives. The centralized cooperative produces more than the decentralized cooperative when $\frac{6(d-A)}{9-4 / r-1 / k}<\frac{4(d-A)}{8-2 / r-1 / k}$, i.e., $k<\frac{2 r}{15 r-2}$. The result regarding the production level is formulated in proposition 6 .

Proposition 6 The equilibrium production level is higher (lower) in the decentralized than in the centralized cooperative when $k>(<) \frac{2 r}{15 r-2}$.

Figure 6 presents proposition 6 .

The efficient governance structure is defined as the governance structure creating the highest value, while taking into account the communication and production level choices in the second and third stage of the game. When $k \leq \frac{\left.5 r+1-\sqrt{7 r^{2}-10 r+1}\right)}{20+18 r}$, and $r$ satisfies $r \in[(5+3 \sqrt{2}) / 7, \infty)$, the profit is higher in the centralized cooperative due to

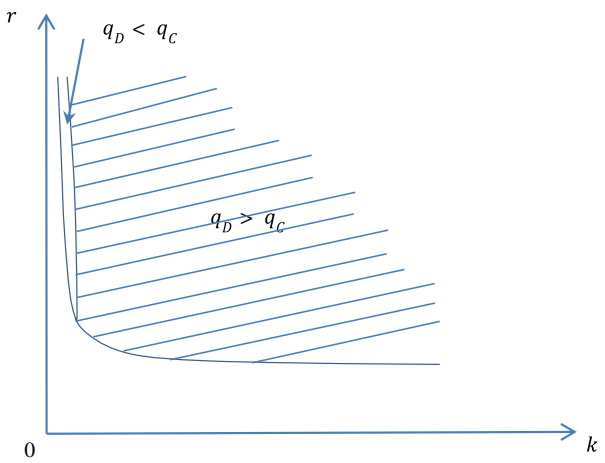

Fig. 6 Comparison of production levels in the two cooperatives 
its two advantages: it internalizes the negative production externalities, it generates a higher VC level, and it results in a higher price per unit sold. When $\frac{\left.5 r+1-\sqrt{7 r^{2}-10 r+1}\right)}{20+18 r}$ $<k<\frac{\left.5 r+1+\sqrt{7 r^{2}-10 r+1}\right)}{20+18 r}$, and $r$ satisfies $r \in[(5+3 \sqrt{2}) / 7, \infty)$, the decentralized cooperative has a higher profit level due to the high equilibrium $\mathrm{VC}$ level and costs in the centralized cooperative. When $k>\frac{\left.5 r+1+\sqrt{7 r^{2}-10 r+1}\right)}{20+18 r}$, and $r$ satisfies $r \in[(5+3 \sqrt{2}) / 7, \infty)$, the decentralized cooperative starts suffering from its overproduction and the underinvestment of the $\mathrm{VC}$, and the loss of surplus is larger than the costly communication in the centralized cooperative. This makes the centralized cooperative efficient again. However, when $r<(5+3 \sqrt{2}) / 7$ and regardless of $k$, the profit level is always lower in the decentralized cooperative than the centralized cooperative. This is due to that when $r$ is small, the VC level is lower in the centralized cooperative, and therefore, the costly $\mathrm{VC}$ in the centralized cooperative becomes insignificant. The advantage of the internalization of the negative production externalities dominates. The result regarding the efficient governance structure for all possible values of the communication cost parameters is formulated in proposition 7 .

Proposition 7 The profit level is higher (lower) in the decentralized cooperative than the centralized cooperative when $r \in[(5+3 \sqrt{2}) / 7, \infty)$ and $k \in\left(\frac{\left.5 r+1-\sqrt{7 r^{2}-10 r+1}\right)}{20+18 r}\right.$, $\left.\frac{\left.5 r+1+\sqrt{7 r^{2}-10 r+1}\right)}{20+18 r}\right)$ otherwise).

We present proposition 9 in Fig. 7.

\section{De Producent Versus Harvest House}

This section presents the two cooperatives in terms of the parameters of the model. With the description of the two cooperatives, we formulate the following assumptions of the four parameters in our model. First, the communication cost coefficients $r$ and $k$ are higher in Harvest House than in De Producent. This due to the different

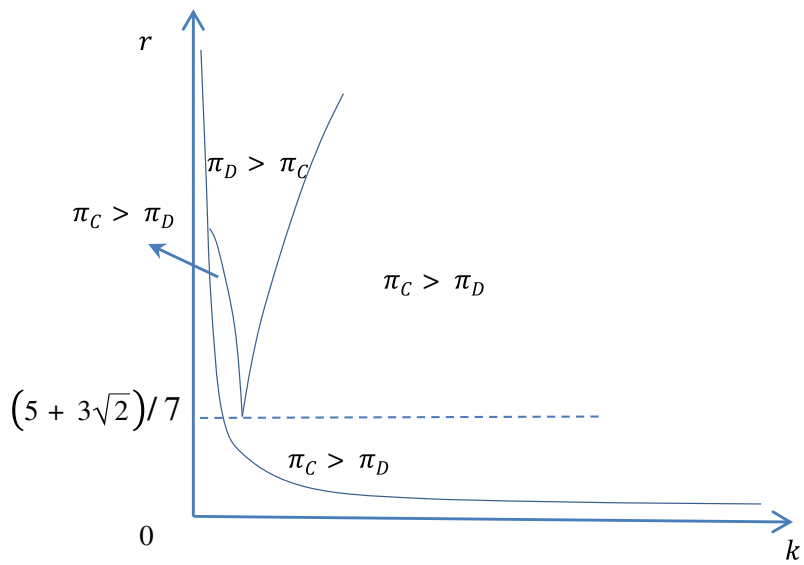

Fig. 7 Comparison of profit levels in the two cooperatives 
Table 3 Comparison of parameters between De Producent and Harvest House

\begin{tabular}{llr}
\hline Member heterogeneity determines: & $r$ & $r_{H}>r_{P}$ \\
& $k$ & $k_{H}>k_{P}$ \\
\hline Product feature determines: & $d$ & $d_{H}<d_{P}$ \\
& $A$ & $A_{H}<A_{P}$ \\
\hline
\end{tabular}

compositions of the membership of the two cooperatives. There is only one product in De Producent, while there are four products in Harvest House. Additionally, product groups in Harvest House have large and small growers, while the farmers owning De Producent have similar sizes. Therefore, member heterogeneity is higher in Harvest House than in De Producent. This makes it relatively more difficult to communicate both horizontally and vertically in Harvest House than in De Producent. However, Harvest House has separated the tomato group and paprika group in its governance structure to facilitate the HC. This lowers the parameter $r$ to the level of De Producent. Moreover, the demand and the fixed production cost have to be considered as well since they are different in different cooperatives. Due to product differentiation, the price of cheese (De Producent) is relatively higher than that of vegetables (Harvest House), and the fixed production cost of cheese (De Producent) is relatively higher than that of vegetables (Harvest House). Table 3 summarizes these observations regarding

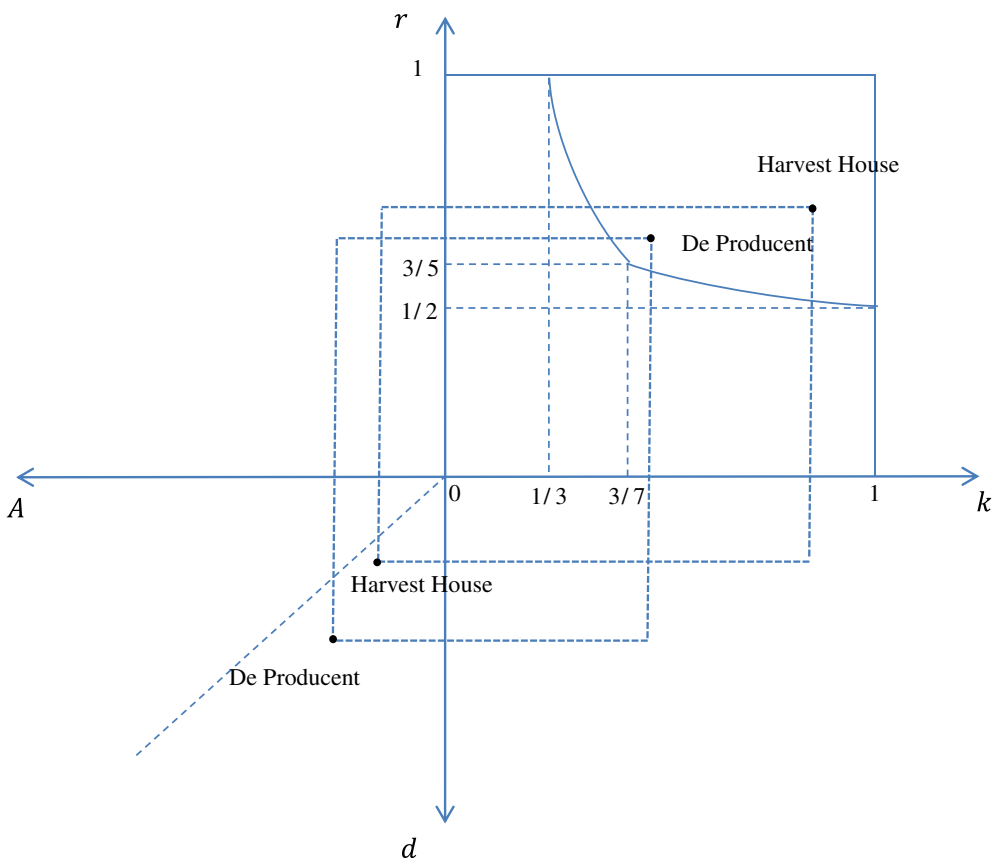

Fig. 8 De Producent and Harvest House in terms of $r, k, d, A$ 


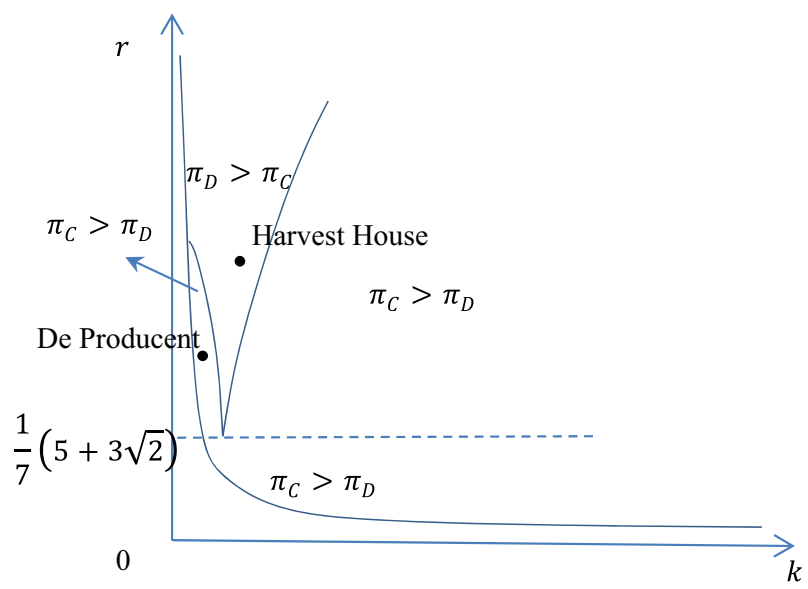

Fig. 9 De Producent versus Harvest House

the parameters of these two cooperatives, where $\mathrm{H}$ represents Harvest House and $\mathrm{P}$ represents De Producent.

Figure 8 presents the two cooperatives in terms of the (relative) values of the four parameters of the model, taking into account the assumption $d>A>0$ and $\left\{\begin{array}{l}\frac{1}{3}<k \leq \frac{3}{7}, \frac{k}{4 k-1}<r<1 \\ \frac{3}{7}<k<1, \frac{4 k}{9 k-1}<r<1\end{array}\right.$.

In order to compare De Producent and Harvest House, we combine Figs. 7 and 8 to illustrate proposition 7. Due to $d-A$ is constant, Fig. 9 is depicted with $r$ on the vertical axis and $k$ on the horizontal axis. From Fig. 9, the parameters of the two cooperatives align with the finding of proposition 7. When $r$ is lower and $k$ is small, the centralized cooperative is efficient, i.e., De Producent. When $r$ is higher and $k$ is in the middle range, the decentralized cooperative is efficient, i.e., Harvest House.

The different communication levels and governance structures of these two cooperatives may also be due to the nature of the product and the innovation strategies. Specifically, the vegetable cooperative has various ways of processing/ packaging. Therefore, HC is more important for improving the process innovation, and a decentralized structure is adopted to facilitate this. The cheese cooperative has identical packaging, but various flavors are developed. Therefore, VC and product innovation are more important for a cheese cooperative, and a centralized structure is adopted to apply this strategy.

In other cooperatives, the situation may differ. However, we claim that the general conclusions are applicable: (1) if process innovation is important for the cooperative, a decentralized governance structure should be adopted to secure the $\mathrm{HC}$ in order to create process innovation. The different communication levels and governance structures of these two cooperatives may also be due to the nature of the product and the innovation strategies. Specifically, the vegetable cooperative has various ways of processing/packaging. Therefore, $\mathrm{HC}$ is more important for 
improving the process innovation, and a decentralized structure is adopted to facilitate this. The cheese cooperative has identical packaging, but various flavors are developed. Therefore, VC and product innovation are more important for a cheese cooperative, and a centralized structure is adopted to apply this strategy. In other cooperatives, the situation may differ. (2) If the product innovation is the focus of a cooperative's strategy, a centralized governance structure should be adopted to implement intensive $\mathrm{VC}$, in order to secure product innovation. In addition, the communication cost has to be considered. Member heterogeneity and distance of the members are examples that influence the communication cost. Our results show that when communication costs are small or large (intermediate), the centralized (decentralized) cooperative is efficient.

\section{Conclusion and Future Research}

In this paper, the relationship between communication, innovation, and (de)centralization in cooperatives is investigated. $\mathrm{HC}$ and $\mathrm{VC}$ associate with different types of innovation. $\mathrm{HC}$ is related to process innovation, while $\mathrm{VC}$ is related to product innovation. The intensity of the two types of communication depends on the costs of the two types of innovation. A decentralized cooperative is characterized by the members taking individually the vertical communication and production decisions, while these decisions are made by the CEO of the cooperative enterprise in a centralized cooperative. Horizontal communication decisions are made by members individually in both cooperatives. The decentralized cooperative has a tendency to overproduce due to the negative production externalities and to generate insufficient $\mathrm{VC}$ due to the positive externalities in the provision of product quality. An advantage of the decentralized cooperative is that the costs of $\mathrm{VC}$ are carried by the various members, as opposed to the centralized cooperative in which all $\mathrm{VC}$ are generated by the CEO. We find that when both communication cost coefficients are small and large, the centralized cooperative dominates, when both communication cost coefficients are in an intermediate range, the decentralized cooperative dominates.

There are various possibilities for future research. First, the current model provides a start to model the choice of communication policy of supplier-owned enterprises. In practice, a much richer menu of communication devices is used and developed to address a variety of issues. For example, an important theme in cooperatives is the development of membership policies to foster involvement, commitment, and trust between the farmers and the cooperative enterprise. These membership policies involve several means to stimulate $\mathrm{HC}$ as well as VC. Another example is social capital in cooperatives (Deng 2015). Second, VC in our model is a beneficial activity. It is related to product innovation and increases therefore the product market price. However, other types of VC are present in cooperatives. Farmers communicate extensively with the general manager about the transactions between the farm and the cooperative enterprise, and the strategy of the cooperative, due to their large financial involvement in the cooperative. Cook (1995) identifies five general problem sets in cooperatives: free-rider problem, horizon problem, portfolio problem, control problem, and the influence costs 
problem. At least two of these five problem sets, i.e., the control problem and the influence costs problem, involve VC. However, the nature of VC in these problem sets seems to be quite different and requires therefore different modelling. Third, research regarding the governance of cooperatives is usually highlighting the differential incentives of various board models (Bijman et al. 2013). Such research addresses the relationship between a board representing the members and the professional management of the cooperative enterprise. However, the relationship between the professional management and the many individual members in terms of management may be more important in the creation of value, and is challenging and complex (Cook 1994). Research regarding the governance of cooperatives will therefore benefit from putting more emphasis on the managerial importance of developing and implementing communication policies by distinguishing various types of communication and recognizing their differential impacts. Finally, we stated at the beginning of the "De Producent and Harvest House"section that the information about the two cooperatives are descriptions. These descriptions are valuable because they signal important phenomena in cooperatives. However, it will be informative and important to have future research using a rigorous case study methodology in the collection of data.

\section{Appendix}

\section{Payoffs in Decentralized/Centralized Cooperative (given HC and VC)}

The mathematical steps to obtain the comparative statics in the centralized and centralized cooperatives given $\mathrm{HC}$ and $\mathrm{VC}$ are presented in Table 4 below:

\section{Payoffs in Decentralized/Centralized Cooperative (given HC)}

Similarly, the mathematical steps to obtain the comparative statics in the centralized and centralized Cooperative without $\mathrm{HC}$ are presented in Table 5 below:

\section{Payoffs in Decentralized/Centralized Cooperative}

The mathematical steps to obtain the comparative statics in the centralized and centralized Cooperative, see Table 6, are presented below:

Proof Proposition 1 From Table 4 we obtain that given $\mathrm{HC}$ and VC, $Q_{D}=\frac{2}{3}$ $(d-A+\bar{v}+\bar{h})$ and $Q_{C}=\frac{1}{2}(d-A+\bar{v}+\bar{h})$. We can see that always $Q_{D}>Q_{C}$.

Proof Proposition 2 From Table 4 we obtain that given $\mathrm{HC}$ and VC, $\pi_{D}=\frac{2}{9}$ $(d-A+\bar{v}+\bar{h})^{2}-r \bar{h}^{2}-k \bar{v}^{2}$ and $\pi_{C}=\frac{1}{4}(d-A+\bar{v}+\bar{h})^{2}-r \bar{h}^{2}-2 k \bar{v}^{2}$. The difference between the joint profit of the centralized cooperative and the decentralized cooperative is $\frac{1}{36}(\mathrm{~d}-\mathrm{A}+\bar{v}+\bar{h})^{2}-k \bar{v}^{2}>0$ when $\mathrm{VC}$ is 0 .

Proof Proposition 3 From Table 5 we obtain that without $\mathrm{HC}, V_{D}=\frac{2(d-A)}{9-1 / k}$ and $V_{C}=\frac{2(d-A)}{8-1 / k}$. Therefore, the $\mathrm{VC}$ level is always higher in the centralized cooperative for all possible values of $k$. 


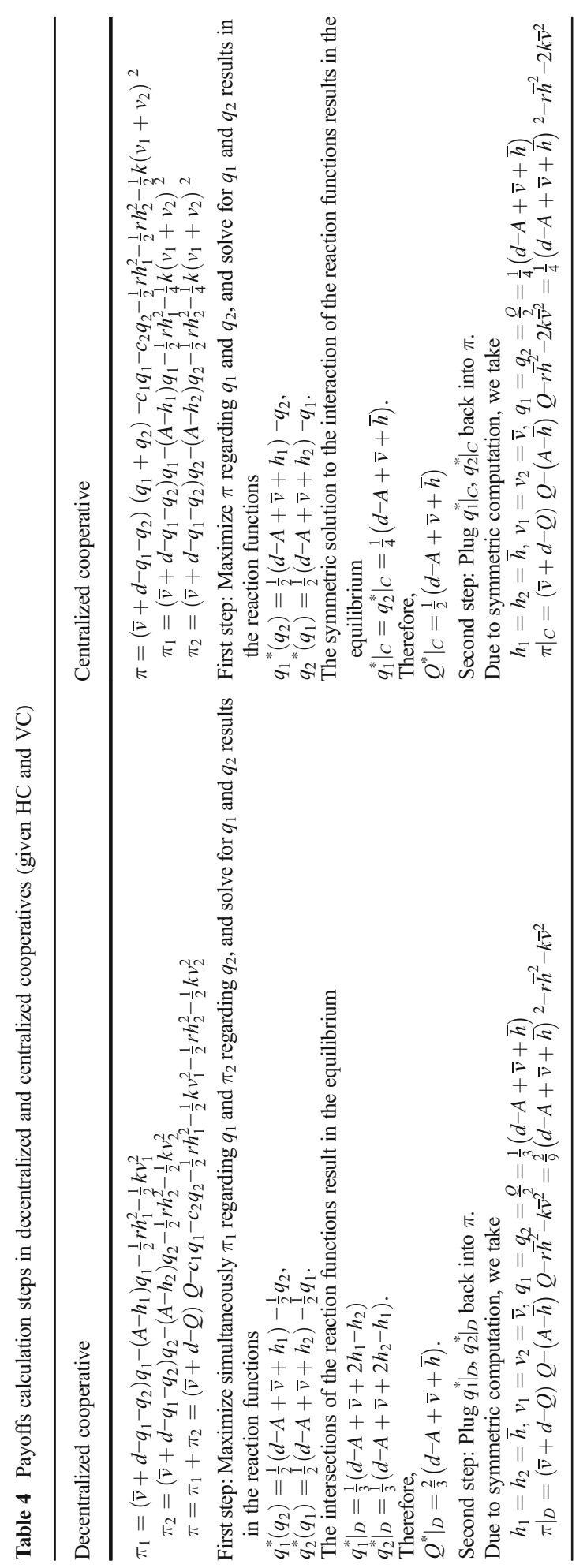




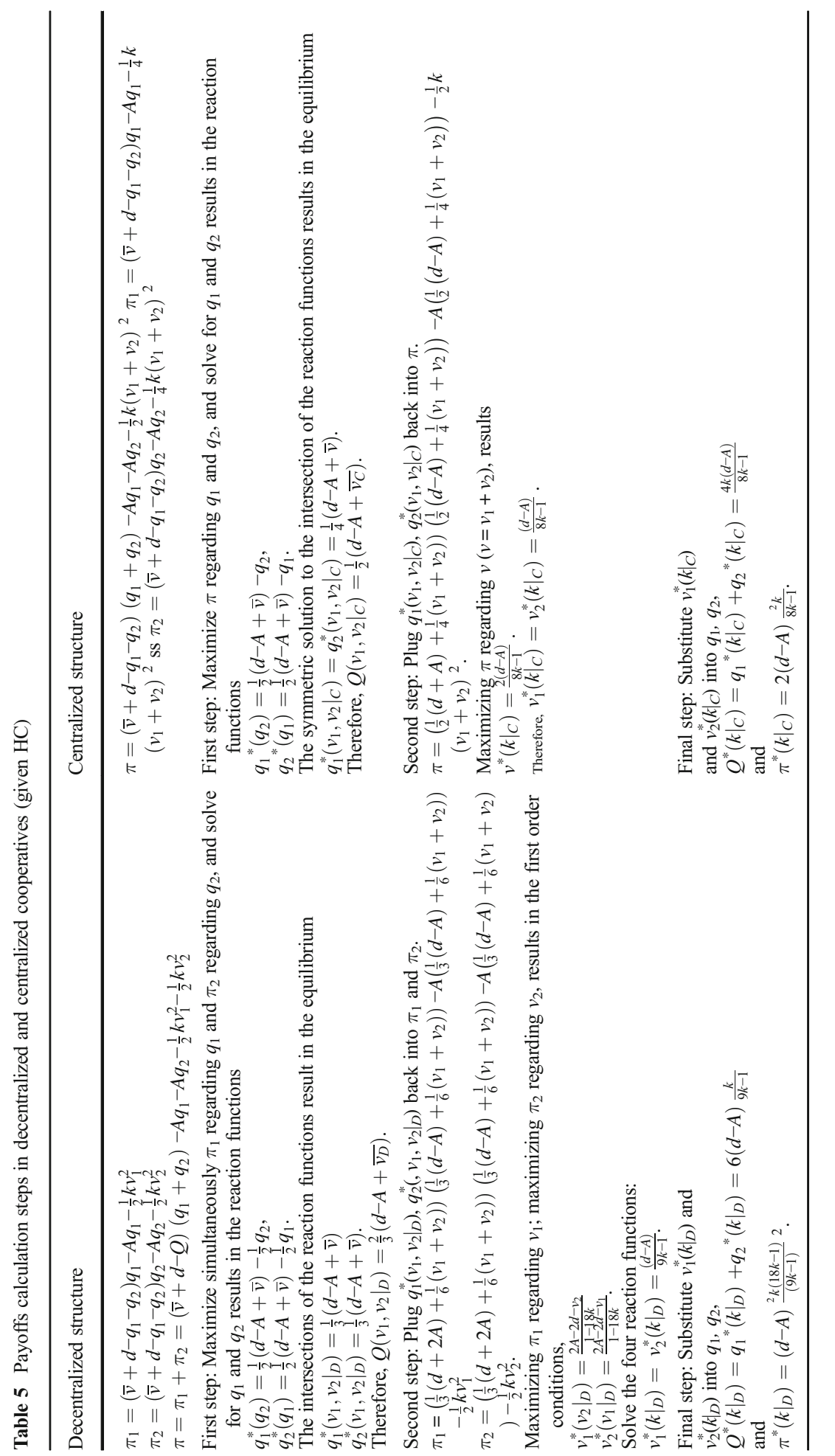




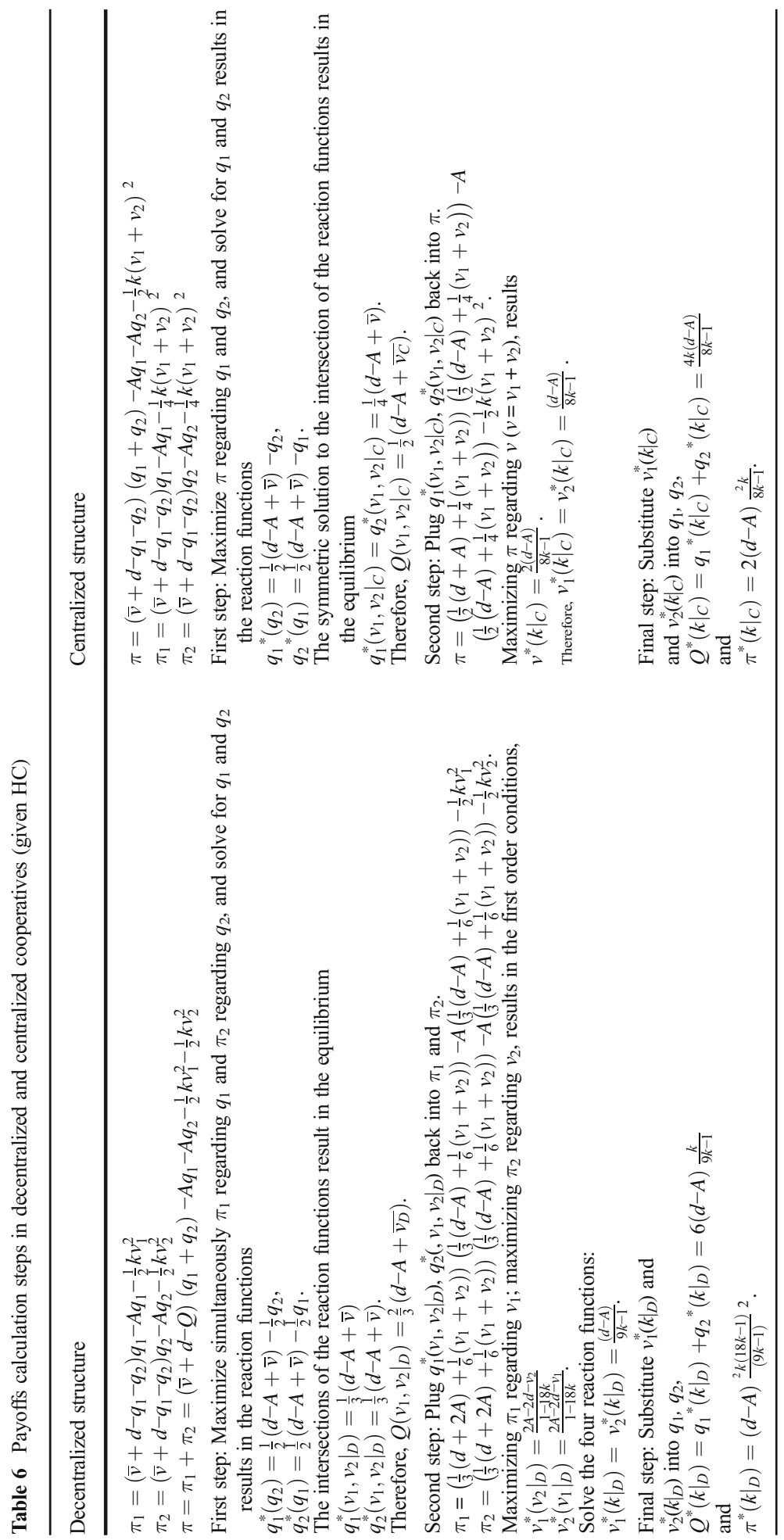


Proof Proposition 4 From Table 5 we obtain that without HC, $Q_{D}=\frac{6(d-A)}{9-1 / k}$ and $Q_{C}=\frac{4(d-A)}{8-1 / k}$. The production level is higher in the decentralized cooperative than the centralized cooperative when $\frac{6(d-A)}{9-1 / k}>\frac{4(d-A)}{8-1 / k} \Leftrightarrow 3\left(8-\frac{1}{k}\right)>2\left(9-\frac{1}{k}\right) \Leftrightarrow 21-\frac{3}{k}>18-\frac{2}{k} \Leftrightarrow 6$ $>\frac{1}{k} \Leftrightarrow k>\frac{1}{6}$. Therefore, the production level is higher in the decentralized cooperative than in the centralized cooperative when $k>1 / 6$.

Proof Proposition 5 From Table 5 we obtain that without HC, $\pi_{D}=(d-A) \frac{2}{(18-1 / k)}^{(9-1 / k)}$ and $\pi_{C}=2(d-A) \frac{2}{8-1 / k}$. The profit level is higher in the decentralized cooperative than in the centralized cooperative when $(d-A) \frac{2}{(18-1 / k)}^{2}>2(d-A)^{2}-8-1 / k \Leftrightarrow\left(18-\frac{1}{k}\right)$ $\left(8-\frac{1}{k}\right)>2\left(9-\frac{1}{k}\right)^{2} \Leftrightarrow 144 k^{2}-26 k+1>162 k^{2}-36 k+2 \Leftrightarrow 18 k^{2}-10 k+1<0 . \quad$ Th e roots of the equation $18 k^{2}-10 k+1=0$ are $k=\frac{5 \pm \sqrt{7}}{18}$. Therefore, $\pi_{D}>\pi_{C}$ holds when $k \in\left(\frac{5-\sqrt{7}}{18}, \frac{5+\sqrt{7}}{18}\right)$. To conclude, the profit level is higher (lower) in the decentralized cooperative than in the centralized cooperative when $\mathrm{k} \in\left(\frac{5-\sqrt{7}}{18}, \frac{5+\sqrt{7}}{18}\right)$ (otherwise).

Proof regarding the equilibrium communication levels (Fig. 4): From Table 6, we obtain that with both $\mathrm{HC}$ and $\mathrm{VC}, H C_{D}=\frac{8(d-A)}{r(9-1 / k)-4}$ and $H C_{C}=\frac{4(d-A)}{r(8-1 / k)-2}$. The HC level in the decentralized cooperative is higher than in the centralized cooperative when $\frac{8(d-A)}{r(9-1 / k)-4}>\frac{4(d-A)}{r(8-1 / k)-2} \Leftrightarrow 2 r\left(8-\frac{1}{k}\right)-4>r\left(9-\frac{1}{k}\right)-4 \Leftrightarrow 16-\frac{2}{k}>9-\frac{1}{k} \Leftrightarrow k>\frac{1}{7}$. Therefore, when $k>(<) \frac{1}{7}$, the $\mathrm{HC}$ level is higher (lower) in the decentralized cooperative than in the centralized cooperative.

From Table 6, we obtain that with both $\mathrm{HC}$ and $\mathrm{VC}, V C_{D}=\frac{2(d-A)}{k(9-4 / r)-1}$ and $V C_{C}=\frac{2(d-A)}{k(8-2 / r)-1}$. The VC level is higher in the decentralized cooperative than in the centralized cooperative when $\frac{2(d-A)}{k(9-4 / r)-1}<\frac{2(d-A)}{k(8-2 / r)-1} \Leftrightarrow k\left(8-\frac{2}{r}\right)-1<k\left(9-\frac{4}{r}\right)-1 \Leftrightarrow 8-\frac{2}{r}$ $<9-\frac{4}{r} \Leftrightarrow r>2$. Therefore, when $r>(<) 2$, the VC level is higher (lower) in the centralized structure than in the decentralized structure.

Proof Proposition 6 From Table 6, we obtain that with both $\mathrm{HC}$ and $\mathrm{VC}, Q_{D}$ $=\frac{6(d-A)}{9-4 / r-1 / k}$ and $Q_{C}=\frac{4(d-A)}{8-2 / r-1 / k}$. The production level is higher in the decentralized cooperative than in the centralized cooperative when $\frac{6(d-A)}{9-4 / r-1 / k}>\frac{4(d-A)}{8-2 / r-1 / k} \Leftrightarrow \frac{3}{9-4 / r-1 / k}>$ $\frac{2}{8-2 / r-1 / k} \Leftrightarrow k>\frac{2 r}{15 r-2}$.

Proof Proposition 7 From Table 6, we obtain that with both the equilibrium HC and $\mathrm{VC}, \pi_{D}=\frac{(\mathrm{d}-\mathrm{A})^{2}(18-16 / \mathrm{r}-1 / \mathrm{k})}{(9-4 / \mathrm{r}-1 / \mathrm{k})^{2}}$ and $\pi_{C}=\frac{2(\mathrm{~d}-\mathrm{A})^{2}}{(8-2 / \mathrm{r}-1 / \mathrm{k})}$. The profit level is higher in the decentralized cooperative than in the centralized cooperative when $\frac{(d-A)^{2}(18-16 / r-1 / k)}{(9-4 / r-1 / k)^{2}}$ $>\frac{2(\mathrm{~d}-\mathrm{A})^{2}}{(8-2 / \mathrm{r}-1 / \mathrm{k})} \Leftrightarrow(18 k r-16 k r)(8 k r-2 k-r)>2(9 k r-4 k-r)^{2} \Leftrightarrow\left(-\frac{20}{r}-18\right) k^{2}+\left(10+\frac{2}{r}\right)$ $k-1>0 \Leftrightarrow\left(\frac{20}{r}+18\right) k^{2}-\left(10+\frac{2}{r}\right) k+1<0$. The roots of the equation $\left(\frac{20}{r}+18\right) k^{2}-$ 
$\left(10+\frac{2}{r}\right) k+1=0 \quad$ a r e $\quad k=\frac{\left.5 r+1 \pm \sqrt{7 r^{2}-10 r+1}\right)}{20+18 r}$ w h e n $\quad r \in\left(0, \frac{1}{7}(5-3 \sqrt{2})\right)$ or $r \in$ $\left[\frac{1}{7}(5+3 \sqrt{2}), \infty\right)$. Due to the conditions of $k$ and $r$, see footnote $3, r$ is larger than $\frac{1}{7}(5-3 \sqrt{2})$, hence $r \in\left(0, \frac{1}{7}(5-3 \sqrt{2})\right)$ is eliminated. Therefore, when $\frac{\left.5 r+1-\sqrt{7 r^{2}-10 r+1}\right)}{20+18 r}$ $<k<\frac{\left.5 r+1+\sqrt{7 r^{2}-10 r+1}\right)}{20+18 r}$ and $r \in\left[\frac{1}{7}(5+3 \sqrt{2}), \infty\right)$, the profit level is higher in the decentralized cooperative than the centralized cooperative.

Open Access This article is distributed under the terms of the Creative Commons Attribution 4.0 International License (http://creativecommons.org/licenses/by/4.0/), which permits unrestricted use, distribution, and reproduction in any medium, provided you give appropriate credit to the original author(s) and the source, provide a link to the Creative Commons license, and indicate if changes were made.

\section{References}

Albæk, S., \& Schultz, C. (1998). On the relative advantage of cooperatives (pp. 397-401).

Alonso, R., Dessein, W., \& Matouschek, N. (2008). When does coordination require centralization? American Economic Review, 98(1), 145-179.

Bijman, J., Hendrikse, G., \& Oijen, A. V. (2013). Accommodating two worlds in one organisation: changing board models in agricultural cooperatives. Managerial and Decison Ecnomics, 34, 204-217.

Bulow, J., \& Klemperer, P. (1996). Auctions versus negotiations. American Economic Review, 86(1), 180-194.

Cechin, A., Bijman, J., Pascucci, S., \& Omta, O. (2013). Decomposing the member relationship in agricultural cooperatives: implications for commitment. Agribusiness, 29(1), 39-61.

Chaddad, F., \& Iliopoulos, C. (2013). Control rights, governance, and the costs of ownership in agricultural cooperatives. Agribusiness, 29(1), 3-22.

Christensen, L. T., \& Cornelissen, J. (2011). Bridging corporate and organizational communication: review, development and a look to the future. Management Communication Quarterly, 25(3), 383-414.

Cook, M. L. (1994). The role of management behavior in agricultural cooperatives. Journal of Agricultural Cooperation, 9, 42-58.

Cook, M. L. (1995). The future of U.S. agricultural cooperatives: a neo-institutional approach. American Journal of Agricultural Economics, 77(5), 1153-1159.

Cremer, J., Garicano, L., \& Prat, A. (2007). Language and the theory of the firm. The Quarterly Journal of Economics, 1, 373-407.

Deng, W. (2015). Social Capital and Diversification of Cooperatives. Erasmus University.

Falvey, R., Poyago-Theotoky, J., \& Teerasuwannajak, K. T. (2013). Coordination costs and research joint ventures. Economic Modelling, 33, 965-976.

Garicano, L., \& Wu, Y. (2012). Knowledge, communication, and organizational capabilities. Organization Science, 23(5), 1382-1397.

Goodman, J. D. (1994). It's a matter of governance - the angry members may be right. Management Quarterly, 35(1), 2-5.

Helmberger, P., \& Hoos, S. (1962). Cooperative enterprise and organization theory. Journal of Farm Economics, 44(2), 275-290.

Hendrikse, G. W. J., \& Feng, L. (2013). Interfirm cooperatives. In Handbook of economic organization, edward elgar (pp. 501-521). Cheltenham: Edward Elgar.

Jablin, F. M., \& Putnam, L. (2001). The New Handbook of Organizational Communication: Advances in Theory, Research, and Methods. Sage.

Mérel, P. R., Saitone, T. L., \& Sexton, R. J. (2009). Cooperatives and quality-differentiated markets: strengths, weakness, and modeling approaches. Journal of Rural Cooperation, 37(2), 201-224.

Milgrom, P., \& Roberts, J. (1992). Economics, Organization and Management (Prentice= H). Prentice-Hall. Mussa, M., \& Rosen, S. (1978). Monopoly and product quality. Journal of Economic Theory, 18, 301-317.

Patrucco, P. P. (2008). The economics of collective knowledge and technological communication. The Journal of Technology Transfer, 33(6), 579-599. 
Pelz, D. C., Munson, F. C., \& Jenstrom, L. L. (1978). Dimensions of innovation. Journal of Technology Transfer, 3(1), 35-49.

Prosser, G. a. (1995). The role of incentives in the deployment of technologies from cooperative R\&D. The Journal of Technology Transfer, 20(2), 13-17.

Robotka, F. (1947). A theory of cooperation. Journal of Farm Economics, 29(1), 94-114.

Schultz, D. E., Tannenbaum, S., \& Lauterborn, R. F. (1994). The new marketing paradigm. Integrated marketing communications. Chicago: NTC Business Books.

White, J. (1997). Gower Handbook of Internal Communication. In E. Scholes (Ed.), Aldershot: Gower.

Williamson, O. E. (2000). The New Institutional Economics: Taking Stock, Looking Ahead. Journal of Economic Literature 38(3), 595-613. 